\title{
R11 - COMPARAÇÃo DE METOdOLOGIAS DE ACOPLAMENTO UTILIZADAS NA PLATAFORMA DE MICROARRANJOS LÍQUIDOS
}

Leila Botelho Rodrigues da Silva ${ }^{1}$, Marcelle Bral de Mello ${ }^{1}$, Bernardo de Oliveira $\underline{\text { Loureiro }}^{1}$, Bruna de Paula Fonseca e Fonseca ${ }^{1}$, Edimilson Domingos da Silva ${ }^{1}$, Antônio Gomes Pinto Ferreira ${ }^{1}$, Christiane de Fátima Silva Marques ${ }^{1}$.

${ }^{1}$ Laboratório de Tecnologia Diagnóstica, Bio-Manguinhos, Fiocruz

Objetivos: Neste trabalho foi feita uma comparação de duas metodologias de acoplamento de antígenos utilizadas na plataforma de microarranjos líquidos, visando sua transferência para a produção. Este estudo faz parte de um projeto do Programa de Reativos para Diagnóstico de Bio-Manguinhos/Fiocruz, que prevê o desenvolvimento de um multiteste para triagem sorológica de bolsas de sangue nos hemocentros brasileiros.

Metodologia: Na plataforma de microarranjos líquidos, antígenos e/ou anticorpos são acoplados a microesferas magnéticas de poliestireno que atuam como suporte sólido para a captura de moléculas em amostras biológicas. A reação de acoplamento é baseada na ligação covalente de grupamentos carboxílicos presentes na superfície das microesferas às aminas primárias existentes nos antígenos e/ou anticorpos. Foram avaliadas duas metodologias de acoplamento de antígenos/anticorpos à microesferas. A metodologia 1 consiste na realização do ensaio em placas de 96 poços (volume final de $100 \mathrm{uL}$ ), que permite o acoplamento de um milhão de microesferas por vez. A metodologia 2 se utiliza de microtubos de $1 \mathrm{~mL}$, onde a reação de acoplamento ocorre em volume de 500uL, com quantidades superiores de microesferas. Para comparação entre as metodologias foram acoplados seis antígenos específicos de HIV, HTLV, HBcAg, Sífilis, Chagas e HCV e um anticorpo (anti-IgG) à diferentes códigos de microesferas. Foram acoplados um milhão e cinco milhões de microesferas nas metodologias 1 e 2, respectivamente, para cada antígeno/anticorpo. O resultado do acoplamento foi avaliado por meio de ensaio padrão, onde as microesferas foram expostas a amostras de soro previamente caracterizadas para cada antígeno/anticorpo acoplado. Também foi avaliado um pool de amostras sabidamente positivas para cada agravo de interesse. Os resultados das reações, apresentados na forma da mediana da intensidade de fluorescência (MFI), foram comparados por meio de um Teste T. 
Resultados: $\mathrm{O}$ rendimento final médio obtido no acoplamento com a metodologia 1 foi de $91,4 \%$, e de 76,4\% na metodologia 2. Dos seis antígenos avaliados, quatro (HIV, HTLV, Sífilis e HCV) apresentaram valores de MFI significativamente maiores $(p<0,05)$ quando acoplados com a metodologia 2, assim como o único anticorpo avaliado.

Conclusão: A metodologia 1 permite a realização de múltiplos acoplamentos em uma mesma placa, podendo ser automatizada com o auxílio de uma lavadora de placas. A metodologia 2 exige que os acoplamentos sejam feitos separadamente, mas permite que maiores quantidades de microesferas sejam acopladas de uma só vez. Apesar do rendimento da metodologia 1 ser superior ao obtido na metodologia 2, os valores de MFI obtidos nas duas metodologias mostraram-se bastante diferentes. Como resultado, a metodologia 2 apresentou maior capacidade de diferenciação entre amostras positivas e negativas, uma característica bastante desejável, em se tratando de um ensaio para triagem sorológica de bolsas de sangue. Assim, conclui-se que a metodologia 2 é mais adequada à aplicação do multiteste em desenvolvimento. 